\title{
ПОДЕЛОЧНЫЕ КАМНИ СЕВЕРНОГО КАВКАЗА (МРАМОРНЫЙ ОНИКС)
}

\author{
В.М. Газеев ${ }^{1}$, А.Г. Гурбанов ${ }^{2}$, О.А. Гурбанова ${ }^{3}$
}

\begin{abstract}
Аннотация. На основании изучения геологических отчетов, научных публикаций и собственных марирутных исследований установлен перечень поделочных камней, встречающихся на Северном Кавказе. Приведено краткое геологическое описание наиболее типичных проявлений и месторождений популярного поделочного камня - мраморного оникса. Показано, что в регионе встречается несколько морфологических типов его проявлений: 1 - в поверхностных плащеобразных телах травертинов; 2 - в карстовых полостях известняков и гипсов титонского яруса; 3 - отдельные жилы и линзообразные тела. Выявлена цветовая гамма мраморных ониксов Северного Кавказа. Отмечено, что их ивет варьирует от желтоватого с оттенками медового, янтарного и красноватого до насыщенно-коричневого и темно-коричневого цвета. Рассмотрен вероятный возраст этих образований.

Ключевые слова: поделочные камни, мраморный оникс, травертин, карстовые полости, кальцит, арагонит.
\end{abstract}

\section{ВВЕДЕНИЕ}

Северный Кавказ - это курортный регион и зона с развитой туристической инфраструктурой. Круглый год его многочисленные здравницы, санатории, туристические базы, кемпинги, альплагеря, горнолыжные отели и гостиницы встречают отдыхающих со всей России и многих зарубежных стран. Важно также отметить, что кавказский регион богат красивыми поделочными камнями, места их расположения легкодоступны, а сами камни легко обрабатываются (отмываются от посторонних налетов, полируются и т. д.). Однако, если пройти по зонам торговли в аэропортах и вокзалах региона и по небольшим рынкам в парках и местах массового отдыха, легко убедиться, что собственно товаров местных производителей не так уж много. Это, как правило, изделия из шерсти, сборы трав, разнообразный мед, поделки из дерева, картины, реже Кисловодский фрарфор, кинжалы и серебро кубачинских мастеров (Дагестан) и обработанные турьи рога. Довольно примитивный каменный рынок специализируется в основном на перепродажах поделок из других регионов России, Индии и Китая. Интересующиеся любители поделочных камней, после долгих поисков, обнаружат в небольшом ассортименте коллекционные минералы, полировки пород и ископаемую фауну, иногда шары, пирамидки, меркабы и грубоватые столешницы, обычно со срезом аммонита. Изучение литературных источников показывает, что и раньше дела обстояли не лучше. Для сравнения можно привести некоторые примеры других стран, где существует коллекционный и ювелирный рынок камней и фауны, построенный на местном, вполне сопоставимом с Северным Кавказом, материале, например: ювелирный рынок Доминиканской республики широко использует местные ювелирноподелочные камни, такие как ларимар и черный коралл; Новая Зеландия - нефрит; Армения и Мексика - различно окрашенный обсидиан; Израиль - илатский камень, состоящий из малахита и азурита; Пакистан, Аргентина - мраморный оникс. Из российских регионов достаточно упомянуть уральский регион с его поделками из яшм, змеевиков, родонита. В качестве примера показаны поделки из мраморного оникса, предлагаемые в торговых центрах Аргентины, широко распространенных от Ушуая до Буэнос-Айреса (рис.1).

На Большом Кавказе поисками цветных камней занимались различные структурные подразделения СКТГУ и «ФГУГП Кавказгеолсъемка». В XX веке открыты месторождения и многочисленные проявления поделочных камней: гагата; адыгеита (жад корейский); змеевиков; лиственитов; серпофита; стеатита; бовенита; родингитов; скарноидов; актинолититов; тремолититов; мторолита; пектолита и ксонотлита; авантюрина; яшмы; обсидиана; цветных кремней и халцедонов; жадеита; нефрита; гипса (алебастр и селенит); черного и белого мрамора; декоративного мраморовидного, оолитового и органогенного известняка; мраморного оникса. $[8,2]$.

Мраморным ониксом (далее МО) принято называть плотные, слабо просвечивающиеся, агрегаты кальцита или арагонита, окрашенные в мягкие желтые, медовые, розовые, кремовые, синеватые, зеленоватые и коричневые тона с характерным ленточным или концентрическим узором, обусловленным ритмичным чередованием тонких полосок с разной интенсивностью окраски. В самой отдаленной древности МО обратил на себя вни-

\footnotetext{
${ }^{1}$ Газеев Виктор Магалимович - к. г.-м. Н., с. н. с. КНИО ВНЦ РАН г. Владикавказ, н. с. ИГЕМ РАН, г. Москва (gazeev@igem.ru).

ГУрбанов Анатолий Георгиевич - к. г.-м. н., в. н. с. ИГЕМ РАН, г. Москва, в. н. с.. КНИО ВНЦ РАН, г. Владикавказ (ag.gurbanov@yandex.ru).

${ }^{3}$ Гурбанова Ольга Александровна - к. х. н., ассистент кафедры минералогии и кристаллохимии геологического факультета МГУ им. М.В. Ломоносова, г. Москва (gur_o@mail.ru).
} 


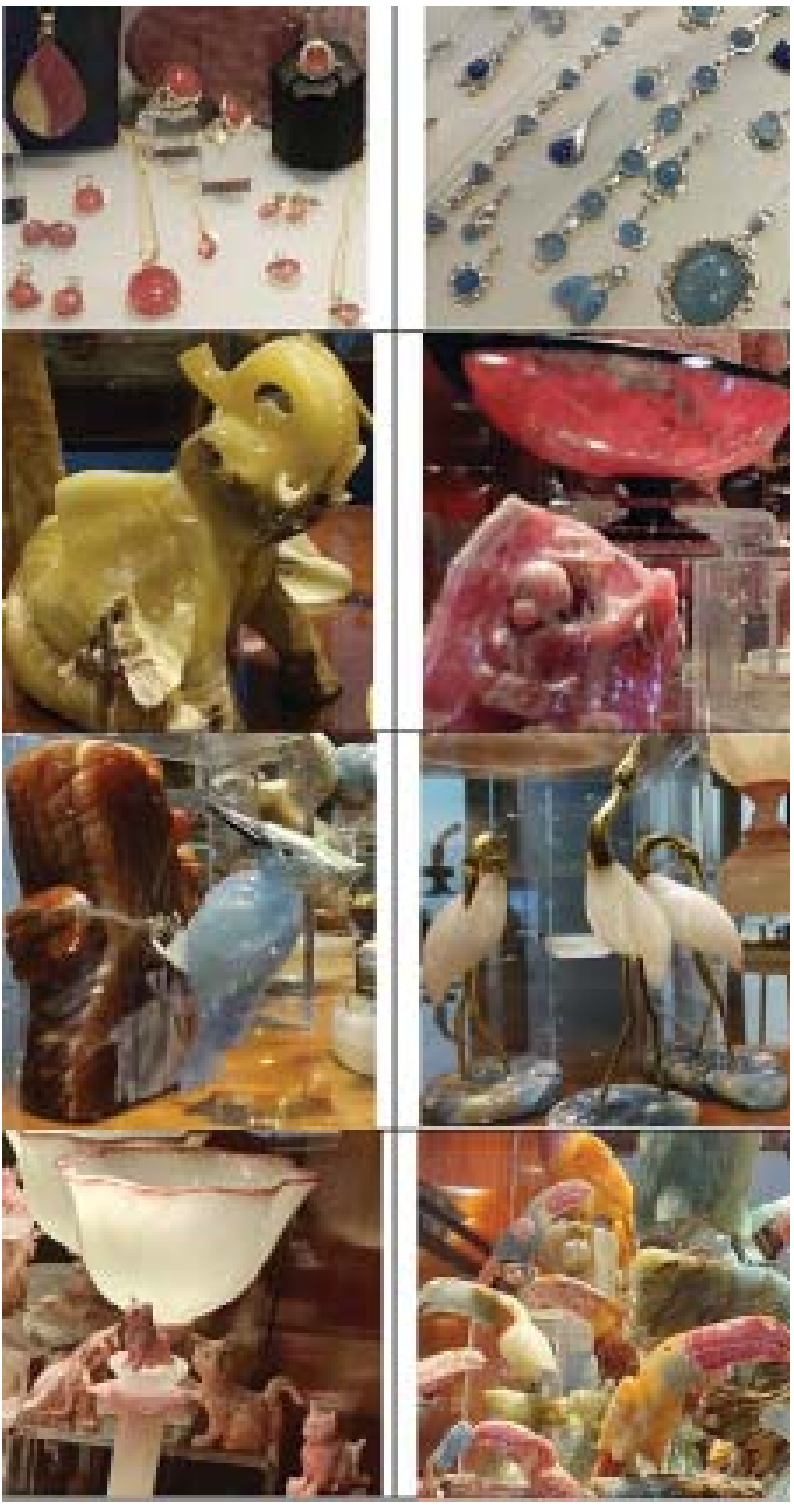

Puc.1. Украшения и поделки из разноцветного мраморного оникса Аргентины

мание человека благодаря своим декоративным свойствам, красивой окраске в широкой цветовой гамме, изящному рисунку, полупрозрачности, легкости в обработке и хорошей сохранности в изделиях. Как поделочный камень использовался еще в Вавилоне, Карфагене, доисторическом Египте. Во времена древнего Рима был известен как «восточный алебастр». Современное название происходит от древнегреческого слова «онис» - коготь.

«Издавна необработанные ониксы люди носили как амулеты против злых сил, полагая, что сама их фрорма определяет защитные свойства камня. МО считали хорошим поглотителем негативной энергии, он способен «вытягивать» боль. МО применяли при заболеваниях нервной системы и депрессиях. Считалось, что он снимает стрессы, способствуя обретению эмоционального равновесия и самоконтроля, а изделия с оник- сом обостряют слух, омолаживают, укрепляют память. Литотерапевты советовали прикладывать полосатые ониксы к воспалившимся местам и считали, что ониксы улучшают кальциевый обмен в организме, поэтому их рекомендовали для постоянного ношения пожилым людям» [5].

Собственно ониксом принято считать тонкополосчатые агрегаты с контрастными белыми и темными слоями. Полосчатый агрегат, имеющий кальцитовый или арагонитовый состав, называют МО и обычно применяют для изготовления всевозможных поделок, шкатулок, ваз, письменных приборов, скульптур, а также как облицовочный материал. В связи с низкой твердостью в качестве украшений МО используется редко.

Настоящая публикация является логическим продолжением ранее опубликованных статей, посвященных развитию минералогического туризма на Северном Кавказе [1, 2].

\section{КРАТКОЕ ОПИСАНИЕ ПРОЯВЛЕНИЙ МРАМОРНОГО ОНИКСА}

Лагонакское проявление. Расположено в Адыгейской республике, в 24 км к северо-западу от ст. Даховская (рис. 2). Проявление представляет собой карстовую промоину, глубиной 4 м и 2,5 м в диаметре, которая переходит в горизонтальную двухкамерную щелевидно-гротовую галерею. Размеры первой камеры 3 × 2,5 × 1,9 м, второй - 7,5 × 2,5 × 4,0 м. Во второй камере присутствуют многочисленные сталактиты и сталагмиты высотой от 5 см до 1,5 м и диаметром от 10 до 30 см. Срастаясь между собой, обе эти формы образуют единые колонны сталагнаты. Значительная их часть обрушена и за-

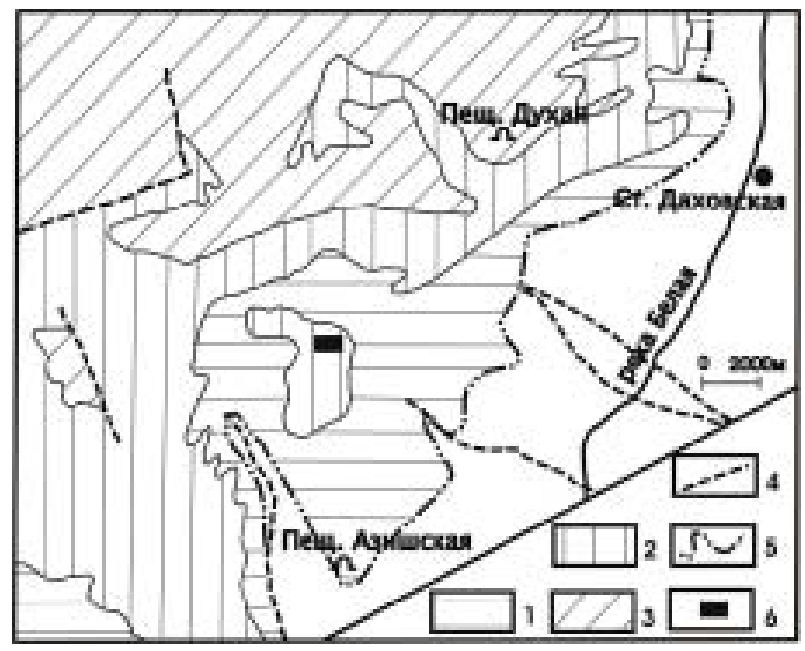

Puc. 2. Схематическая геологическая карта плато «Лагонаки»

Условные обозначения: (1-2) - поздняя юра: 1 - известняки, 2 - известняки и пестроцветные глины титонского яруса (площадь с развитым карстом, перспективная на обнаружение проявлений МО); 3 - нижний мел - известняки мергели, песчаники и глины; 4 - разрывные нарушения; 5 куэстовая гряда; 6 - проявление МО 
хоронена в донной глине, которая покрыта рыхлой коркой травертина. Качество МО различное.

Отмечены плотные медово-желтые слабо просвечивающиеся и светлые тонко-полосчатые разновидности. Образцы имеют концентрический рисунок, хорошо полируются, однако часто их качество ухудшают радиальные трещинки и мелкие каверны. Новые проявления МО здесь могут быть открыты при обследовании других карстовых полостей.

Машукское проявление. Расположено в районе города Пятигорска. На карте (рис. 3) показаны выходы травертинов, содержащих пропластки и прожилки МО, прослеживающиеся в виде непрерывного полукольца на севере, востоке и юге г. Машук. Травертины здесь формировались в несколько этапов в течение всего четвертичного периода. В относительно молодых перекрывающих их покровах встречаются единичные и маломощные жилы, а в более древних количество и мощность жил возрастает. На горе имеются заброшенные карьеры, где раньше добывали травертин для строительных целей, вблизи Перскальской скалы и западнее поселка Каменоломня. В карьерах встречаются линзовидные прослои медово-желтых, янтарных и медово-красных МО мощностью 5-10 см и протяженностью 2-3 м, просвечивающиеся на глубину до $1 \mathrm{~cm}$. На юге и юго-востоке, в районе Горячей горы среди древних травертинов обнажается серия кальцитовых и арагонитовых жил мощностью до одного метра [9].

Ахметовское месторождение. Расположено на территории Лабинского района Краснодарского края в междуречье Ецока и Гарнуха (правые притоки р. Большой Лабы). Ближайшим населенным пунктом является станица Ахметовская. Площадь проявления представляет собой низкогорную расчлененную местность с превышением над долинами рек на 200-250 м. На плоских поверхностях хребта развит карст. Формирование основных запасов мраморного оникса здесь связано с длительным процессом осаждения карбоната из термальных источников в полостях выщелачивания, образовавшихся в залежах гипса. Такие полости являются своеобразными «ловушками» для образования мощных натечных корок, сталактитов и сталагмитов на их стенках. Продуктивными являются карбонатные и глинисто-гипсоносные толщи титонского яруса, сформированные в мелководных, прибрежно-лагунных условиях, в верхнеюрское время. Большинство известных проявлений в районе месторождения приурочено к зоне контакта верхнеюрской и нижнемеловой толщ. Единичные проявления отмечены и в зонах тектонических нарушений в известняках валанжинского яруса нижнего мела. Глыбы и обломки мраморного оникса наблюдаются и в аллювиально-делювиальных отложениях, где встречается желтоватый, коричневый, медовый полупрозрачный, реже концентрически зональный, иногда радиально-лучистый

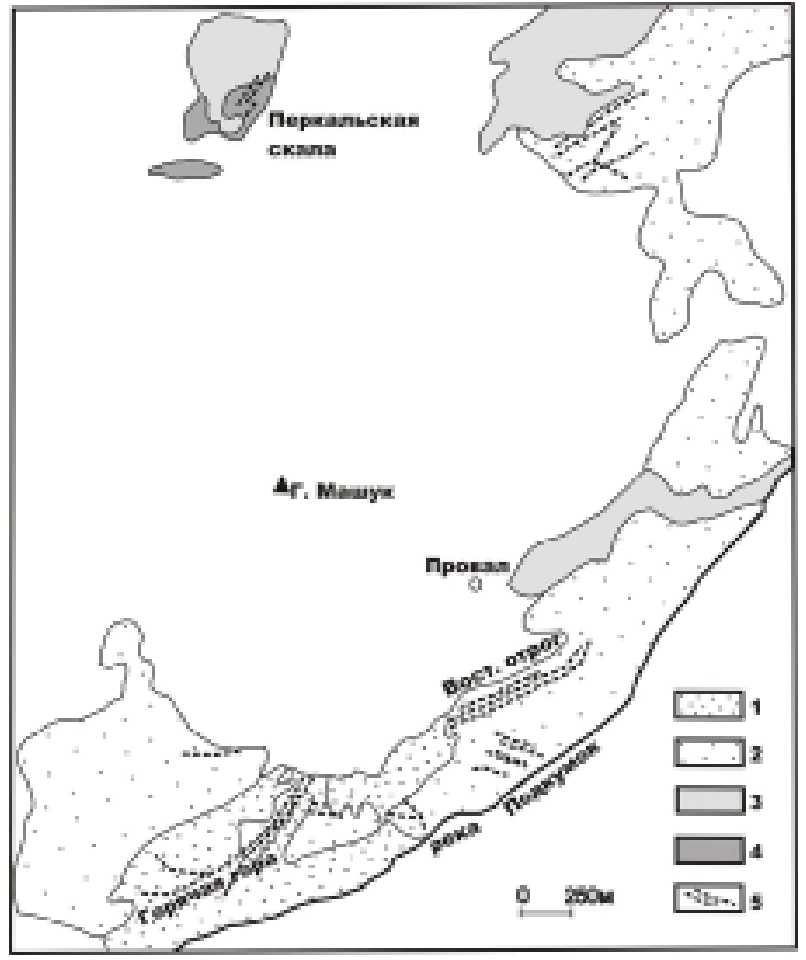

Puc. 3. Карта выходов травертинов горы Машук [9]

Условные обозначения: (1-4) - травертины: 1 - современные до вюрмских, 2 - рисские и рис-вюрмские, 3 - миндельские и миндель-рисские, 4 - апшеронские до гюнцких; 5 кальцитовые и арагонитовые жилы

МО. Наиболее привлекательны образцы медовокоричневого тона. В процессе геологоразведочных работ в 1983-84 годах была произведена оценка запасов МО, которые составили 181 тонну. В процессе опытно-промышленной отработки извлечена 101 тонна, и она была полностью использована на Ахалцихском камнеобрабатывающем предприятии $[4,6]$. По сообщению С.В. Попова, жилы арагонита встречаются и восточнее, в Зеленчукском районе (Скалистый хребет, гора Джисса).

Эльбрусское месторождение. Участок с шестью проявлениями МО, сконцентрированными в нижнеюрской толще, находится в долине р. Кубани, вблизи поселка Эльбрусский. Все проявления, вне зависимости от состава вмещающих пород, контролируются системами внутрипластовых и секущих трещин. Отмечается несколько его разновидностей: ярко-коричневый, со слабо выраженным полосчатым рисунком, просвечивается на глубину до 1,5-2,0 см; радиально-лучистый, коричневый, с хорошо выраженной иризацией; крупнополосчатый, в верхней части преимущественно белый, а в нижней - ярко-коричневый, с узловатым узором. В некоторых случаях МО выполняет небольшие пустоты карстового типа, в которых встречаются тонкопластинчатые, крупно-почечные, сталактитовые, сталагмитовые агрегаты. Структура оникса сравнима с уральским малахитом, как по чистоте линий, так и по завершенности рисунка. Сравне- 
ние с известными карлюкскими МО Туркмении, обладающими высокими декоративными качествами, показывает, что эльбрусские МО приближаются к ним, а во многих случаях не уступают эталонным образцам [3].

Проявление Сары-Тюз. Расположено в Карачаево-Черкесской Республике, в левом борту долины р. Кубани, в 5 км выше по руслу от развилки дорог Черкесск - Теберда - Преградная. В нижней части позднеюрской известняковой толщи отмечены линзы светло-коричневого МО, просвечивающегося в пластинках до 2 см [6].

Проявление Кумык-су-2. Расположено в Кабардино-Балкарской Республике. Находится в левом борту долины р. Баксан в километре ниже по течению от жилых построек г. Тырныауза. В русловых отложениях ручья Кумык-су-2 на протяжении 500-700 м встречаются обломки МО размером 0,1-0,5 м. Отмечены две его разновидности - светлая и коричневая, часто присутствующие в одном образце.

Проявление Актопракское. Расположено в правом борту долины р. Чегем в 4 км выше Чегемских водопадов. На высоте 100-150 м над руслом р. Чегем залегают несколько останцов травертинового покрова мощностью до 10 м. В редких полостях встречаются пластинчатые и крупнопочечные образцы темно-коричневого МО. Отдельные жильные тела МО светло-желтого цвета, мощностью до 15 см отмечались в этом районе и в левом борту долины р. Чегем.

Проявление Абайтикауское. Расположено в Алагирском районе Республики Северная ОсетияАлания. В верховьях р. Закка-дон, в 4,5 км выше с. Абайтикау, в среднеюрских аргиллитах расположена плащеобразная залежь МО. Толщина натечных образований 0,1-0,25 м. Оникс темно-коричневый, полосчатый, более светлый к периферии. Часто отмечаются почковидные формы с коническим рисунком. В аллювии встречаются многочисленные угловато-окатанные обломки размером 0,1-0,5 м. МО обладает высокими декоративными свойствами, на которые мало влияют мелкие поры и трещины. Ориентировочные запасы 100 тонн. В этом же районе имеются многочисленные выходы травертинов, которые могут содержать скрытые полости c MO.

Проявление Амусадонское. Расположено вблизи с. Калотикау в правом борту долины ручья Амуса-дон - притока р. Фиагдон. В травертиновом покрове, расположенном в четырех километрах выше устья ручья, встречаются оригинальные наросты, сложенные длинноигольчатыми (до 2 см), радиально расположенными кристаллами коричневого и темно-коричневого арагонита, создающими полусферы-«ежи» с уплощенным основанием диаметром 3-4 см. Эти образования могут быть рекомендованы в качестве коллекционного материала, однако из-за хрупкости иголочек отбор его существенно затруднен.

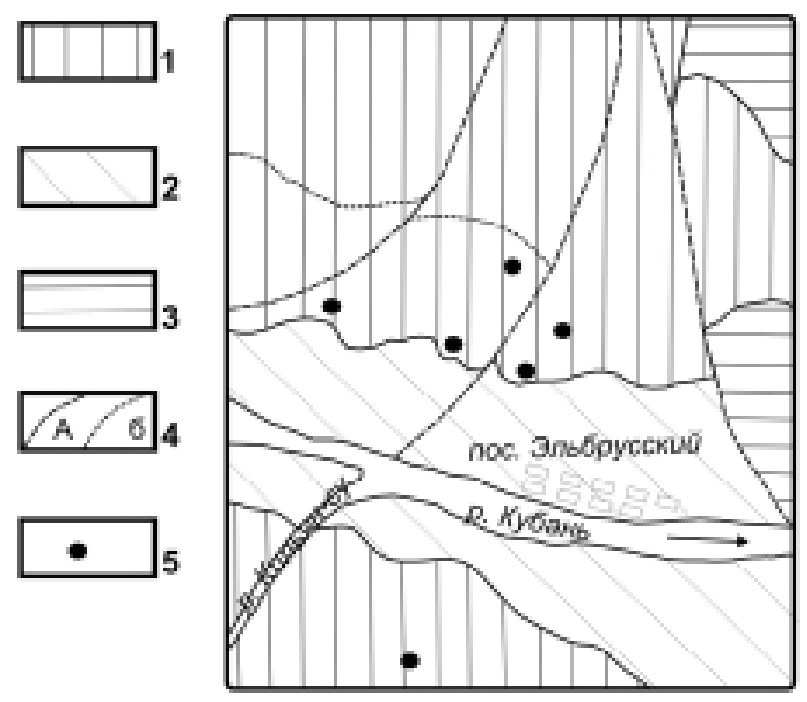

Puc. 4. Схематическая карта проявлений мраморного оникса района пос. Эльбрусский Условные обозначения: 1 - конгломераты, песчаники и алевролиты нижней юры; 2 - вулканогенно-осадочные толщи среднего палеозоя; 3 - кристаллические сланцы; 4a разрывные нарушения; 46 - угольный пласт; 5 - проявления $\mathrm{MO}$

Проявление мраморного оникса «Кина». Расположено в Южном Дагестане, в левом борту долины р. Самур, в 30 км западнее селения Рутул, напротив устья р. Кина. Здесь известна травертиновая залежь площадью $60 \times 100$ м и мощностью 3-15 м, в массе которой имеются пустоты неправильной формы (длиной до 5 м и шириной от 0,5 до 2 м). Стенки пустот покрыты сплошными волнообразными натеками преимущественно арагонитового состава. Отмечаются почковидные, сталактитовые и сталагмитовые образования. Мощность натеков до $30 \mathrm{~cm}$, размеры почек до $20 \mathrm{~cm}$, сталактитов - до 30 см, сталагмитов - до 50-60 см в диаметре при длине до 1 м. На проявлении выявлено несколько разновидностей оникса, не имеющих между собой четких границ и переходов, встречаются как совместно, так и разрозненно. Первая разновидность представлена тонкополосчатым ониксом желтоватого и коричневого цвета. Ширина отдельных полос варьирует от 0,1 до 1-2 см. Мощность прослоев до 10-15 см. Вторая разновидность имеет темно-коричневую окраску, большей частью с шелковистым блеском. Ею сложено большинство почек и сталактитов. Третья разновидность темнокоричневая, стекловидная, встречается в основании сталагмитов и крупных почковидных форм. В целом для проявления «Кина» следует отметить преобладание МО темно-коричневых тонов, рисунок на срезе концентрических фрорм и имитирует окаменелую древесину, а поликонцентрические формы напоминают структуру малахита. По р. Самур отмечены и другие участки с травертином, содержащим MO [8]. 


\section{ОБСУЖДЕНИЕ И ВЫВОДЫ}

Выше приведено краткое описание некоторых проявлений МО. Обращает внимание, что эти объекты практически отмечены на территории всех республик и краев Северного Кавказа. Преимущественно они распространены в полосе развития юрских отложений, но иногда встречаются среди палеозойских (проявление Камыксу-2), меловых и неоген-четвертичных пород. Чаще всего МO ассоциирует с залежами травертина и зонами развития карстовых полостей, реже встречается в виде единичных жил и линз. Возраст травертинов, в связи с тем, что они наложены на современный рельеф, скорее всего четвертичный.

Ониксы, связанные с карстовыми процессами, могут быть древнее. Известны внешне похожие желтые и коричневые карбонаты, встречающиеся в септариях нижнемеловых разрезов, однако они формируются в других условиях и не имеют полосчатого структурного узора. Формирование травертинов и ониксов связано с процессами растворения, переноса и осаждения карбоната. Поэтому они ассоциируют с осадочными породами, однако повышенная температура, реакционная активность и, как следствие, минерализация приповерхностных вод могут быть местами обусловлены влиянием неоген-четвертичных вулканических и магматических процессов. Наиболее очевидно это на примере г. Машук, в недрах которой присутствует остывающий магматический объект неогенового возраста

В связи с тем, что на Северном Кавказе вулканизм широко проявлялся во всем фанерозое, вполне вероятно, что и в более древние, чем неоген, времена происходило образование подобных травертинов и ониксов. Однако приповерхностные условия их формирования и их невысокая твердость приводят к потере этих объектов и исчезновению их декоративных качеств под влиянием эрозионных процессов.

Цветовая гамма ониксов Северного Кавказа варьирует от желтоватого с оттенками медового, янтарного, красноватого до насыщенно-коричневого и темно-коричневого цвета. Качество материала позволяет использовать мраморный оникс Северного Кавказа в камнерезном производстве. Стоимость изделий из МО в Аргентине, в зависимости от их качества и размера, варьирует от десятков до сотен долларов. Как показывает опыт небольших зарубежных камнерезных предприятий, это малозатратный и, при правильной организации, быстро окупаемый бизнес.

\section{ЗАКЛЮЧЕНИЕ}

В результате изучения геологических отчетов, научных публикаций и собственных маршрутных исследований установлено, что на Северном Кавказе присутствуют разнообразные поделочные камни, в том числе и месторождения МО. Показано, что здесь встречается несколько морфологических типов его проявлений: 1 - поверхностные плащеобразные тела травертинов с МО; 2 - карстовые полости в известняках титонского яруса с MO; 3 - отдельные жилы и линзообразные тела МО. Выявлена цветовая гамма ониксов Северного Кавказа, варьирующая от желтоватого с оттенками медового, янтарного, красноватого до насыщеннокоричневого и темно-коричневого цвета. Качество материала и его запасы позволяют использовать местный мраморный оникс в камнерезном производстве. При правильной организации можно развивать на основе поделочных камней Северного Кавказа относительно малозатратный и окупаемый бизнес.

Работа подготовлена при поддержке гос. темы регистрационный номер ААAА-A19-119040190054-8 в КНИО ВНЦ РАН.

\section{ЛИТЕРАТУРА}

1. Газеев В.М., Гурбанов А.Г., Кусраев А.Г., Попов С.В. Перспективы развития минералогического туризма на Северном Кавказе (на примере месторождений коллекционных минералов и поделочных камней) // Вестн. ВНЦ. РАН. Том 16. № 1. 2018. С. 51-60.

2. Газеев В.М., Гурбанов А.Г., Гурбанова О.А., Попов С.В. Коллекционные минералы и поделочные камни в ультрабазитах и базитах Северного Кавказа // Вестн. ВНЦ. РАН. Том 18. № 2. 2018. С. 29-35.

3. Ермолов В.А., Дунаев В.А., Моросейкин В.В. Кристаллографрия, минералогия и геология камнесамоцветного сырья. - М.: Изд-во Моск. Горн.ун-та, 2003. 407 c.

4. Луценко Е.Н., Глазков В.П. Отчет о результатах поисковых работ на цветные камни по Северному Кавказу за 1981-1984г2. // Геол., фоно. СКТГУ г. Ессентуки.

5. Липовский Ю.О. Лечебные и магические камни. СПб:
ООО СЗКЭО, 2005.- М.: «Изд. ДОМ «Кристалл», 2005. 96 с. 6. Новицкий Е.И. Отчет о результатах поисковых работ на мраморный оникс по Северному Кавказу за 1988 г. // Геол., фонод. СКТГУ г. Ессентуки.

7. Письменный А.Я., Сербинов Н.А., Германовский Л.С. Отчет о результатах поисковых работ на ограночное и ювелирно-поделочное сырье на Северном Кавказе в 1974 г. // Геол., фонд. СКТГУ г. Ессентуки.

8. Серебрийский В.И., Седенко В.С. Отчет отряда цветных камней по работам 1988- 91 ге. // Геол., фронд. СКТГУ г. Ессентуки 1991.

9. Тузиков Р.П. О расчленении травертинов горы Машук (район Кавказских Минеральных вод) // Бюллетень комиссии по изучению четвертичного периода. Изд. АН СССР. - M., 1961. C. 141-146. 


\title{
INDUSTRIAL STONES OF THE NORTHERN CAUCASUS
} (ONYX MARBLE)

\author{
V.M. Gazeev ${ }^{1,2}$, A.G. Gurbanov ${ }^{1,2}$, O.A. Gurbanova ${ }^{3}$
}

${ }^{1} \mathrm{PhD}$, Institute of geology of ore deposits, petrography, mineralogy and geochemistry of the Russian Academy of Sciences (IGEM RAS) (gazeev@igem.ru).

${ }^{2}$ PhD, Vladikavkaz Scientific Centre of the Russian Academy of Sciences (VSC RAS) (ag.gurbanov@ yandex.ru).

${ }_{3}^{3}$ PhD, Moscow State University name after M.V. Lomonosov (MSU) (gur_o@mail.ru).

Abstract. Based on a study of geological reports, scientific publications and our own field investigation the list of industrial stones which are occurring at the Northern Caucasus have been established. Briefly geological description of the most typical manifestations and deposits of popularity industrial stones onyx marble have been done. It was shown that in the region there are several morphological types of it manifestations 1 - in surfacial bed bodies of travertines; 2 - in a karst cavity in a limestone and gypsum of the Tithonian stage; 3 - separate veins and lenticular bodies. Colour gamma of onyx marble from northern Caucasus have been revealed. It is note, that their colour is vary from yellow with a shades of honey, amber and red up to saturated broun and dark-brown colour.. Probable age of this onyx marble have been consider.

Keywords: industrial stones, onyx marble, travertines, karst cavity, calcite, aragonite.

\section{REFERENCES}

1. Gazeev V.M., Gurbanov A.G., Kusraev A.G., Popov S.V. Perspektivy razvitiya mineralogicheskogo turizma na Severnom Kavkaze (na primere mestorozhdeniy kollektsionnykh mineralov i podelochnykh kamney) // Vestn. VNTs. RAN. Tom 16. № 1. 2018. S. 51-60.

2. Gazeev V.M., Gurbanov A.G., Gurbanova O.A., Popov S.V. Kollektsionnye mineraly i podelochnye kamni v ul'trabazitakh i bazitakh Severnogo Kavkaza // Vestn. VNTs. RAN. Tom 18. № 2. 2018.S. 29-35.

3. Ermolov V.A., Dunaev V.A., Moroseykin V.V. Kristallografiya, mineralogiya i geologiya kamnesamotsvetnogo syr'ya. - M.: Izd-vo Mosk. Gorn.un-ta, 2003. 407s.

4. Lutsenko E.N., Glazkov V.P. Otchet o rezul'tatakh poiskovykh rabot na tsvetnye kamni po Severnomu Kavkazu za 1981-1984gg. // Geol., fond. SKTGU g. Essentuki.

5. Lipovskiy Yu.O. Lechebnye i magicheskie kamni. SPb: OOO SZKEO, 2005.- M.: «Izd. DOM "Kristall», 2005. $96 \mathrm{~s}$.

6. Novitskiy E.I. Otchet o rezul'tatakh poiskovykh rabot na mramornyy oniks po Severnomu Kavkazu za 1988 g. // Geol., fond. SKTGU g. Essentuki.

7. Pis'mennyy A.Ya., Serbinov N.A., Germanovskiy L.S. Otchet o rezul'tatakh poiskovykh rabot na ogranochnoe i yuvelirno-podelochnoe syr'ye na Severnom Kavkaze v 1974 g. // Geol., fond. SKTGU g. Essentuki.

8. Serebriyskiy V.I., Sedenko V.S. Otchet otryada tsvetnykh kamney po rabotam 1988 - 91 gg. // Geol., fond. SKTGU g. Essentuki 1991.

9. Tuzikov R.P. O raschlenenii travertinov gory Mashuk (rayon Kavkazskikh Mineral'nykh vod) // Byulleten' komissii po izucheniyu chetvertichnogo perioda. Izd. AN SSSR. - M. 1961. S 141-146.

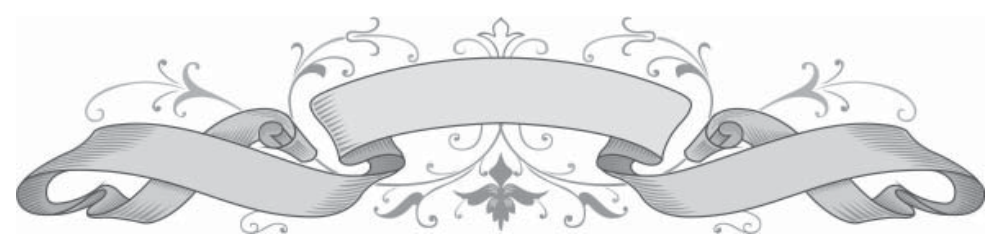

